\title{
Automatic Hand Sanitizer Container to Prevent the Spread of Corona Virus Disease
}

\author{
Puput Wanarti Rusimamto ${ }^{1, *}$ Nurhayati Nurhayati ${ }^{1}$ Eppy Yundra ${ }^{1}$ Reza Rahmadian ${ }^{1}$
}

\author{
Arif Widodo ${ }^{1}$ Much Ade Dermawan ${ }^{1}$ \\ ${ }^{1}$ Department of Electrical Engineering Universitas Negeri Surabaya, Surabaya, Indonesia \\ "Corresponding author. Email: puputwanarti@unesa.ac.id
}

\begin{abstract}
COVID pandemic has influenced human life in various sectors. Various attempts were made to reduce the virus transferring by work from home, social distancing, and also including hand hygiene. So far, most of the available hand sanitizers do not operate automatically. This article aims to make an automatic hand sanitizer where soap and water can come out automatically. Besides that, automated hand sanitizer will make notification to the owner, if the liquid has run out to the smartphone. The infrared (IR) will sense the presence of heat and motion of the object with the distance up to $50 \mathrm{~mm}$. It send data to the Arduino Nano to activate the pump. If the ultrasonic sensor detect the distance of water to he sensor $35 \mathrm{~cm}$ it will send data to node MCU that connect to Blink server. It can transfer the data to the output devices such as smartphones or PC based on the Internet of Things (IoT). The results of the hand sanitizer testing that the system can run smoothly with a minimum detection error of transferring data.
\end{abstract}

Keywords - Automatic hand sanitizer, Infrared sensor, Ultrasonic sensor

\section{INTRODUCTION}

In early 2020, a virus emerged that was spreading rapidly to several countries. The first case related to the virus was reported in Wuhan, Hubei Province [1]. WHO named this disease the 2019 novel coronavirus (2019-nCoV), then changed its name to Coronavirus Disease (COVID-19) which was caused by the virus of Severe Acute Respiratory Syndrome Coronavirus-2 (SARS-Cov-2) [2]. This virus is zoonotic (a virus that is transmitted between animals and humans) and originates from bats [3]. Besides, this virus can also be transmitted from humans to humans [4]. Coronavirus can be transmitted either by air, direct contact, or indirectly. However, it is most commonly spread by droplets. Symptoms caused by this virus include the mild flu, namely a cold, sore throat, cough, fever, and difficulty breathing. In severe cases, Covid-19 can manifest as pneumonia. Patients can develop acute respiratory distress syndrome for a short time and die from multiple organ failure [5].

The existence of this disease has a big impact on both socials and economics. WHO has declared this a pandemic disease and many cities around the world are in a lockdown situation. To prevent the cause of this virus, it can be done by keeping a distance at least 1 meter, avoid going to crowded places, avoid touching the eyes, mouth, and nose when outside, and cleaning hands with soap or alcohol-based hand rub [6]. Providing containers for cleaning fluids in public spaces is a form of Covid-19 prevention, but the provision of containers is currently ineffective because there are parts that are often touched. This could be a point of transmission for Covid-19. Many health actions are carried out using automatic systems including air quality monitoring [7], hand sanitizers [8][9], hand hygiene [10],[11]. Hand sanitizers are an alternative for washing hands during a pandemic. It can be used when and water are not available. Hand sanitizer is also available in several forms such as liquid (spray) or gel [12]. Hand sanitizer is usually made from materials such as alcohol, polyacrylic acid, glycerin, propylene glycol, or plant extracts [13]-[14]. The process of killing germs starts with removing the oil on the skin, then the bacteria in the body will come to the surface. Soap or alcohol will kill bacteria after 
rubbing to your hand. Hand sanitizer is effective against Covid-19 [15].

So far, most of the available hand sanitizers do not operate automatically. This article aims to make an automatic hand sanitizer where soap and water can come out automatically. Besides that, automated hand sanitizer will make notification to the owner, if the liquid has run out to the smartphone. The infrared (IR) will sense the presence of heat and motion of the object and send data to the Arduino Uno so that it can activate the pump. If the water height is less than $10 \mathrm{~cm}$, the ultrasonic sensor will send data to node ESC8266 as a Wifi microcontroller to the output devices such as smartphones or PC based on the Internet of Things (IoT). The results of the hand sanitizer testing that the system can run smoothly with a minimum detection error of transferring data.

\section{MEHOD}

Several steps were carried out in this research to test the Automatic hand sanitizer container has shown in Figure.1. Due to the spread of Covid desease, first we analyse the importance of environment needed for automatic hand sanitizer. The second step we make the literature study about the related article. We design the hardware, examine the product and report the result.

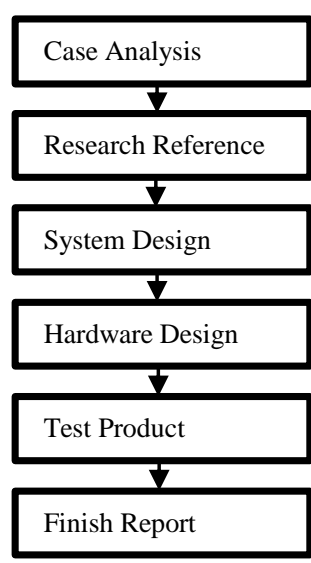

Figure 1. Flowchart Automatic hand sanitizer container

\subsection{System Design}

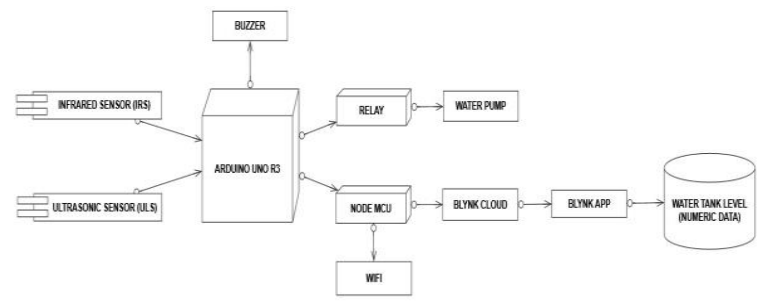

Figure 2. System design automatic hand sanitizer container
Figure 2 demonstrates the design of the Automatic hand sanitizer container system consisting of block an infrared sensor and an ultrasonic sensor. If the infrared sensor sense the motion of hand, it will send data to Arduino. Arduino send data to the relay to activate the water pump. If the distance of water from sensor up to $35 \mathrm{~cm}$ in the clean water container, the sensor will send data to Arduino. Arduino will transfer data to the node MCU as connectivity to a Blynk server. The Blynk App connected to the node MCU. It sends a notification to the user that the water is empty.

\subsection{Hardware Design}

The circuit scheme can be shown in Figure 3 and Figure 4.

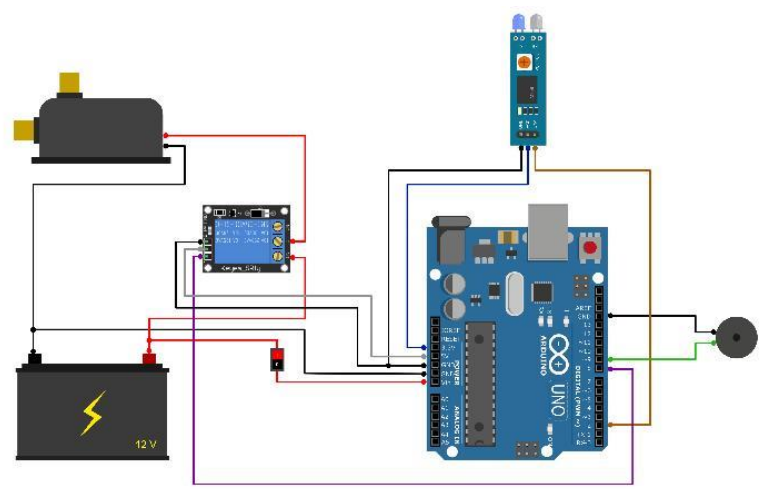

Figure 3. Arduino IR sensor and buzzer circuit

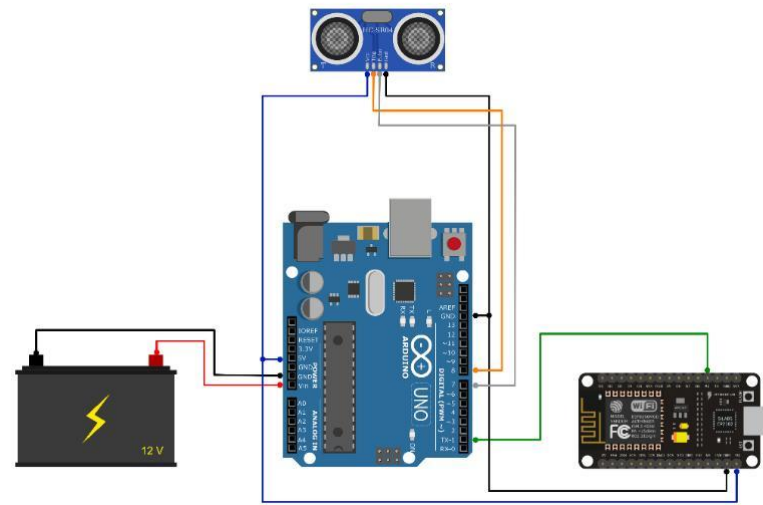

Figure 4. Arduino node MCU ultrasonic circuit

The circuit in this research has two systems that can work simultaneously. In Figure 3, if infrared (IR) senses heat and motion of objects, it will send data to the Arduino Uno so that it can activate the spray pump and the cleaner reaches the hand through a small pipe.

The sensor connected to the Arduino will start working when the device is activated. The ultrasonic sensor in this circuit is used to detect the distance to an object. The circuit in Figure 4 works when the water level is less than $10 \mathrm{~cm}$, the ultrasonic sensor will send data to the node MCU which will then be sent to an output device such as a PC or smartphone as a Wifi microcontroller. 


\section{RESULT AND DISCUSSIONS}

Figure 5 shows a flow chart of the Automatic hand sanitizer container which will automatically dispense water and fill the tank for the hand sanitizer process.

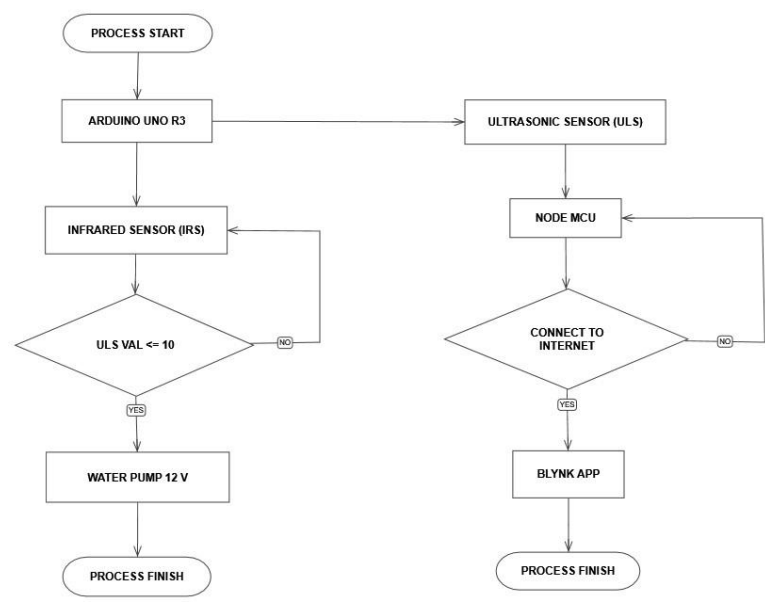

Figure 5. Flow chart automatic hand sanitizer container

The flow chart shows a program that is loaded into the microcontroller. Figure 5 is a flow chart of the Arduino software design. Arduino software will process the input data that has been obtained. The reading data from the infrared sensor and the ultrasonic sensor will be sent to the controller.

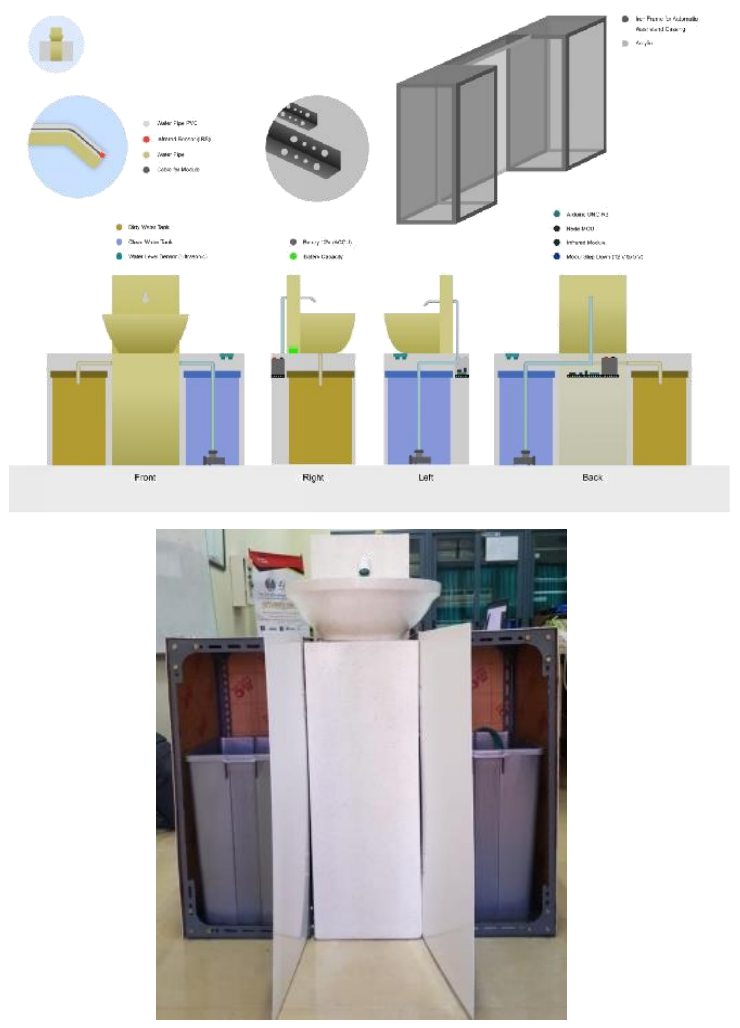

Figure 6. Design automatic hand sanitizer container
Then Arduino will send the value to activate the water pump and node MCU.

This automatic hand sanitizer container uses sensors to detect temperature, object motion, and water level in the tank. The sensor is programmed as automatic water control connected to the microcontroller. This system uses an ultrasonic sensor and an infrared sensor. The ultrasonic sensor will detect if the water level is $35 \mathrm{~cm}$ from the sensor. Data from the ultrasonic sensor will send to Arduino. Processed by Arduino and transferred to the node MCU as connectivity to a Blynk server. Then Blynk App can be connected to the node MCU to get the data that has been sent to the Blynk server. And that application gets to send a notification if the clean water tank has been low. Otherwise, if the undetected water level is less than 10 $\mathrm{cm}$, that application does not send a notification because the input does not receive a signal.

Besides, the infrared sensor connected with the microcontroller will work automatically detect heat and object motion. When the input gets a signal, the water will come out automatically through the pump. This can prevent the spread of bacteria or viruses because there is no need to touch the water(a) pump directly. To find out the results of the ultrasonic sensor system, this research has (b)conducted seven experiments. With an experimental distance of $10 \mathrm{~mm}$ to $70 \mathrm{~mm}$.

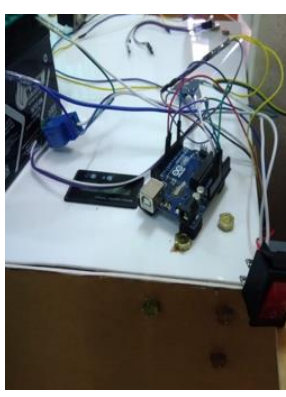

(a)

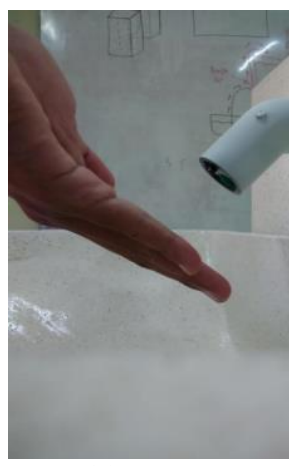

(c)

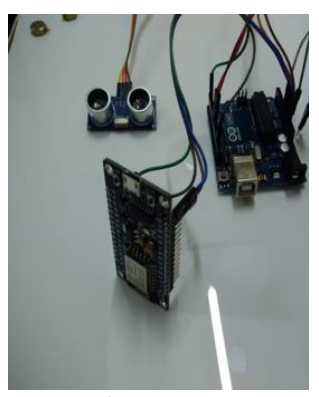

(b)

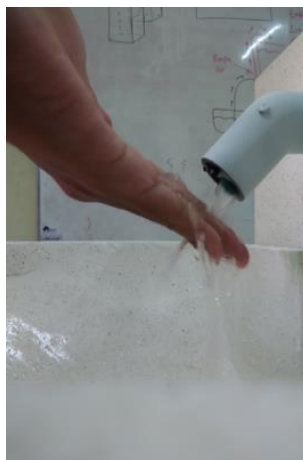

(d)
Figure. 7. (a) Ultrasonic sensor system, (b) Infrared sensor system, (c) Experimental result of infrared sensor for left $>50 \mathrm{~mm}$ (d). Experimental result of infrared sensor for right $<50 \mathrm{~mm}$ 
Table 1. Hand Distance .Experimental Result Of Infrared Sensor

\begin{tabular}{|c|c|}
\hline Distance $(\mathrm{mm})$ & Sensor Information \\
\hline 10 & Sensor Detection \\
\hline 20 & Sensor Detection \\
\hline 30 & Sensor Detection \\
\hline 40 & Sensor Detection \\
\hline 50 & Sensor Detection \\
\hline 60 & Sensor not Detection \\
\hline 70 & Sensor not Detection \\
\hline
\end{tabular}

From the Table 1, it has been set on the work sensitivity of the infrared module, by adjusting it according to the hand distance requirements of the infrared sensor. When experimenting with the tool, the object (hand) has degrees of $0^{\circ}$ thus the object to the infrared sensor is in a parallel position.
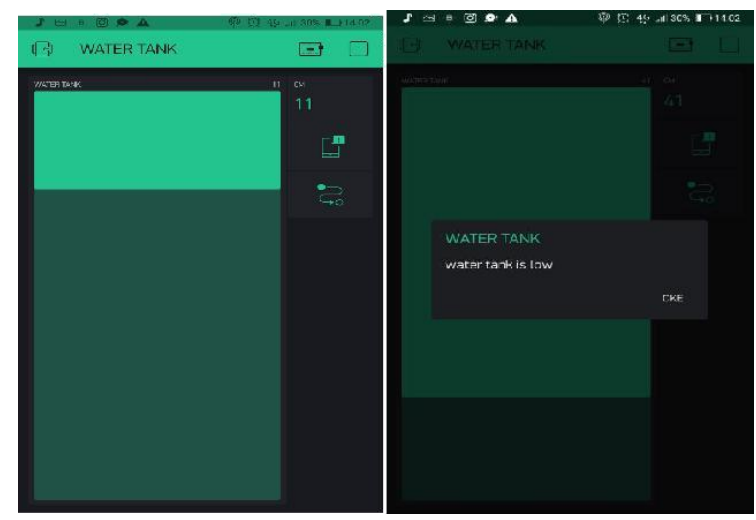

Figure 8. Application design (Blynk app) for monitoring clean water tank

In this display, the user can monitor the contents of the clean water tank. The way this monitoring work is by using an ultrasonic sensor to detect the water level in the tank. The data from the ultrasonic sensor will be processed by a microcontroller in the form of an Arduino. Processed by Arduino and transferred to the node MCU as connectivity to a Blynk server. Then Blynk App can be connected to the node MCU to get the data that has been sent to the Blynk server. That application gets to send a notification if the clean water tank has been low. With information "Water Tank is LOW".

\section{CONCLUSION}

Based on the testing result and discussion, it can be concluded that the results of the automatic hand sanitizer testing can run smoothly with a minimum detection error of transferring data. Infrared can detect the motion up to $50 \mathrm{~mm}$ and ultrsonic sensor can detect the level of water with the distance to the snsor $35 \mathrm{~cm}$. Ultrasonic sensor can send data to the MCU and Blink server and send notification to the user. So that it can be conclude that the system can work smoothly that can prevent the spread of Covid-19.

\section{ACKNOWLEDGMENT}

This research was supported by the Department of electrical engineering at Surabaya State University and was conducted in a telecommunications laboratory.

\section{REFERENCES}

[1] Ing-K L, Chih-C W, et al February 2020 Effective Strategies to Prevent Coronavirus Disease-2019 (Covid-19) Outbreak in Hospital Journal of Hospital Infection

[2] World Health Organization 2020 Naming the Coronavirus Disease (COVID-19) and The Virus that Causes it (Internet) Wolrd Health Organization Available on https://www.who.int/emergencies/diseases/novel -coronavirus-2019/technical-guidance/namingthe-coronavirus-disease-(COVID-2019)-and-thevirus-that-causes-it.

[3] Zakir K, Khayal M, Ali A, Hazir R March 2020 Coronavirus Outbreaks: Prevention and Management Recommendations, Drugs \& Therapy Perspectives

[4] Adityo S, G Martin R, et al March 2020 Coronavirus Disease 2019: Review of Current Literatures, Jurnal Penyakit Dalam Indonesia 7.

[5] Yan-R G, Qing-D C, et al 2020 The Origin, Transmission, and Clinical Therapies on Coronavirus Disease 2019 (Covid-19) OutbreakAn Update on The Status, Military Medical Research 7.

[6] World Health Organization 2020 Naming the Coronavirus Disease (COVID-19) and The Virus that Causes it (Internet) Wolrd Health Organization Available on https://www.who.int/emergencies/diseases/novel -coronavirus-2019/advice-for-public.

[7] "Construction and Application of an Intelligent Air Quality Monitoring System for Healthcare Environment," 2014, DOI: 10.1007/s10916-0140015-3.

[8] T. S. Hong et al., "Systems-Level Quality Improvement A Hand Hygiene Compliance Check System: Brief Communication on a System to Improve Hand Hygiene Compliance in Hospitals and Reduce Infection," 2015, DOI: 10.1007/s10916-015-0253-z.

[9] E. Tartari et al., "Train-the-Trainers in hand hygiene: a standardized approach to guide education in infection prevention and control," 
vol. 4, pp. 1-11, 2019.

[10] S. Angelina et al., "Infection Prevention in Practice Assessing the Hawthorne effect on hand hygiene compliance in an intensive care unit," vol. 2, pp. 10-13, 2020, DOI: 10.1016/j.infpip.2020.100049.

[11] D. J. Birnbach, T. C. Thiesen, L. F. Rosen, M. F. Msn, and K. L. Arheart, "Major Article A new approach to infection prevention : A pilot study to evaluate a hand hygiene ambassador program in hospitals and clinics," AJIC Am. J. Infect. Control, vol. 0, pp. 3-5, 2019, DOI: 10.1016/j.ajic.2019.11.007.

[12] Aliya H June 2016 Antibacterial Effectiveness of Commercially Available Hand Sanitizers International Journal of Biology and
Biotechnology.

[13] Sally F B, Allison E A. et. Al 2007 The Effectiveness of Hand Hygiene Procedures in Reducing The Risks of Interactions in Home and Community Settings Including Handwashing and Alcohol-based Hand Sanitizers American Journal of Infection Control.

[14] Ikegbunam M N, Metuh R C, Anangu L O, Awah N S 2013 Antimicrobial Activity of Some Cleaning Product Again Selected Bacteria International Research Journal of Pharmaceutical and Applied Science (IRJPAS).

[15] Dawodu O, Juwa O August 2017 Production of Hand Sanitizers from Cheap Local Materials Department of Science Laboratory Technology Federal Polytechnic Ede, Osun State Nigeria 